\title{
Facilitators, Barriers and Management Competencies Associated with Schools' Readiness to Implement New Accountable Practices
}

\author{
Nancy Lauzon \\ Faculty of Education, University of Sherbrooke, Canada
}

Copyright $(2017$ by authors, all rights reserved. Authors agree that this article remains permanently open access under the terms of the Creative Commons Attribution License 4.0 International License

\begin{abstract}
Enrolling in the wake of an administrative and educational reform, the implementation of a new "results-based" management is shaking the schools" traditional values and practices, so the culture that characterizes them. In light of the results of three descriptive studies conducted with different groups of stakeholders concerned by this change, this text examines some of the main facilitators and barriers associated with schools' readiness to implement new regulation and evaluation practices. It also shed some light on competencies needed by school principals and their assistants to manage such a cultural change.
\end{abstract}

Keywords School Principals, Change Management, Organizational Culture, Organizational Readiness for School, School Management Competencies, Results-based Management

\section{Introduction: Context and Issues}

Since the late 90s, Quebec schools are the target of numerous attempts initiated by the Ministry of Education and calling on them to rationalize their management and be indebted to it. Thus in the early 2000s, there appears a new measure asking each school to elaborate a Success Plan [1]. This plan was added to an Educational Project that often fails to dwell on the academic performance of students. It required the school management staff to mobilize their teachers around a number of priority actions that could improve the performance of students. Since 2000, other laws have accentuated the obligations to which the institution managers must now comply. One of them requires school boards and their schools to follow a new approach called Results-Based Management. Schools managers must henceforth agree with their school board a Management and Educational Success Agreement, which in turn fits into a partnership agreement between the school board and the Ministry of Education.

This agreement must set the school's targets with respect to perseverance and academic success, in addition to identifying the priorities and planning the actions by which the school will reach the targets put forward. Finally, the school principals have to follow an accountability process through which they will present and justify to their school board the results achieved.

The implementation of these changes was not without pushing, to different degrees, values, habits and practices of schools, so the mission and culture traditionally associated to it. Such a mutation was going to challenge in first place those responsible for the management of the schools. The expectations expressed by school authorities toward school principalship were indeed carrying major cultural challenges. Such changes could only have a major impact on the practice of the school manager's profession. Various researches conducted in Quebec for more than a decade have shown an increase and a complexification of the functions and responsibilities of school managers [2,3]. Other studies relate the loss of autonomy experienced by directions, resulting in a heavy, rigid bureaucratic management insensitive to the new requirements imposed on them $[4,5]$. Such a reduction of their leeway, and the loss of energy that follows, would impinge on the efforts that the management staff must spend to meet the specific needs and priorities of their communities.

In short, the numerous new legal obligations represent a considerable upheaval for school managers. The school is now legally accountable for its results. This shift implies and requires a profound change in its culture and a renewal of its practices. As expressed by Rondeau [6], trigger such a change "requires an effort to change the organizational culture and bring the various actors to change their usual ways of doing things, and to increase their level of professionalism and accountability with respect to outcomes intended". And as assert by Goksoy [7], in this process of

\footnotetext{
Author's translation from French.
} 
change, school managers have to play a leadership role. Therefore, in the context of these major changes, it was and is still expected and understood that the role of the school managers is to lead this change of culture [8], and to convince their staff it is their responsibility to account for the results that the school has set and the use made of resources allocated to it. To do so, the management staff is expected to comply with a framework defined by the school board. It is his responsibility to rally school stakeholders about the way to develop a success action plan that aligns with the process put forward by the school board, to see after its implementation, to set up control and monitoring procedures, and finally to assess and report the results achieved. Although the school managers are getting more familiar in recent years with the steps necessary to complete a planning process, the nature of a results-based success plan requires them to find strategies to ensure staff co-operation and commitment and to provide regulation and assessment practices that allow the school to explain and account for its activities and resources use.

For many school communities, the establishment of this new administrative system will require the school principals and their assistants to undertake an against-cultural change. How to set up an accountable culture within the institution? How to bring the staff to adopt changes in its practices consistent with this plan? How to cope with the resistance and difficulties that will arise? How to develop strategies that will mobilize and facilitate the coming of a new culture? What resources and resources can help them? These are certainly challenges to which managers will have to compete and develop their skills.

\section{Research Questions}

In light of this new contextual change and taking into account the opinions of various groups of actors influencing the implementation of this cultural change at the school level, this articles aims to provide some answers to the following two questions:

- What are barriers and facilitating factors that are likely to influence schools'readiness for change?

- What are the skills and competencies required by school principals to implement new regulation and evaluation practices that fit a school results-based management?

\section{Theoretical Referents}

\subsection{Relevance of Organizational Readiness for Change Concept}

Given the strategic nature of the changes to be made to school culture ${ }^{2}$, the literature on organizational readiness for

\footnotetext{
${ }^{2}$ In practice, the culture of an organization is the set of beliefs and rules of
}

change (ORC) appears particularly relevant. According to Weiner [9], the concept of ORC refers to the collective will and determination of the members of an organization to be psychologically and actively engage in the implementation of change and success. Vakola [10], explicating his multilevel ORC conceptual model, will be more explicit arguing that "Organizational change cannot be effectively implemented without change recipients' willingness to change themselves and support the suggested organizational change program/initiative. These changes cannot occur if employees are not ready for it." Although some authors suggest that the concept of ORC can be studied at the individual, group, and organizational levels $[10,11]$, those having conducted work on organizational change highlight the relevance of studying collective practices changes at the organizational level [12], considering that these changes can be described as complex because they require multiple simultaneous changes. Although this model has been used generally in the field of health care, to our knowledge the ORC concept appears central and crucial to the study of organizational change specifically targeting schools' regulation and evaluation practices, whether upstream or downstream of the management process. It seems indeed justified considering that the cultural change requested from schools requires their members to engage in a collective learning process and to integrate new practices and ways of doing [13].

\subsection{ORC Definition}

After conducting a systematic review of literature Attieh et al. [14] synthesized the existing evidence on conceptual models/ frameworks of ORC in healthcare services and used these as a basis to develop a comprehensive framework of ORC. As a result of their work, these authors conclude that researchers give varied definitions to concepts related to the ORC. According to Nickel et al. [15],

Weiner's definition raises two important points: (1) readiness is a collective state shared by organisation members and (2) readiness is specific to a given change effort. The first point highlights (a) that significantly differing perceptions of readiness among organisation members (e.g., various hospital staff members, employees, and providers) may indicate a lack of shared readiness and (b) that these perceptions are shared among organisation members. The second point emphasises that ORC is specific to each change effort; an organisation may have high readiness for one change effort while possessing low readiness for another.

In the same vein, Holt et al. [11] argued that the concept

conduct that defines "how things work here." These beliefs and rules are not always written, and in fact, most of the members of a company would be hard to explain. But knowing the rules and sharing the beliefs defines a "we" and whoever contravenes finds himself immediately labelled "them." [31]

(Author's translation from French) 
Readiness for Change is a complex multi-dimensional construct including psychological and structural factors that can be located at both individual and organizational levels. For the purposes of this article it seems relevant to retain Gagnon et al. [16], proposed definition which draws on the contribution of the researchers to which we have just referred:

According to Weiner et al., Organizational Readiness for Change (ORC) is defined as a key overarching concept to assess organizational members' collective motivation and capability to implement change. Readiness for change is a comprehensive attitude influenced simultaneously by the nature of the change, the change process, the organization's context and the attributes of individuals.

\subsection{The ORC Framework}

The ORC model was first develop by Weiner [9]. According to Weiner and colleagues, this conceptual model is relevant in identifying ORC determinants [9, 17]. Following his review of literature, Weiner [9] concludes that the great majority of the works done tend to recognize that the collective determination to get involved in a change process seems to be a predictor of successful change. According to Armenakis, Harris and Mossholder [18] this determination manifests itself in beliefs, attitudes, and intentions and is reflected in organizational members' perceptions regarding the extent to which changes are needed and their collective capacity to lead them well. As Haque [19] highlights, the work in this field of knowledge suggests that change agents should first increase the readiness of people and of the organization to change, before attempting for instance to counter resistance. It is precisely this role of change agent that schools' managers must play to prepare their respective communities to the cultural changes to which they are invited.

Finally, as suggested by the work of Eby, Adams, Russell and Gaby [20] Chase [21] and more recently by Shea, Jacobs, Esserman, Bruce and Weiner [22] this perception of organizational readiness for change can be viewed as a continuum from a high degree of preparation (where employees believe that the organization is able to adequately manage change and adapt successfully) to a low degree of preparedness (where employees believe that the organization is not ready to engage in a change process). Consequently, the theory posits that when organizational readiness is high, organizational members are more likely to initiate change, exert greater effort in support of change, and exhibit greater persistence in the face of obstacles or setbacks during implementation. The likely outcome is greater consistency and quality of intervention delivery (i.e., effective implementation). Here is the conceptual framework developed by Weiner [9]:

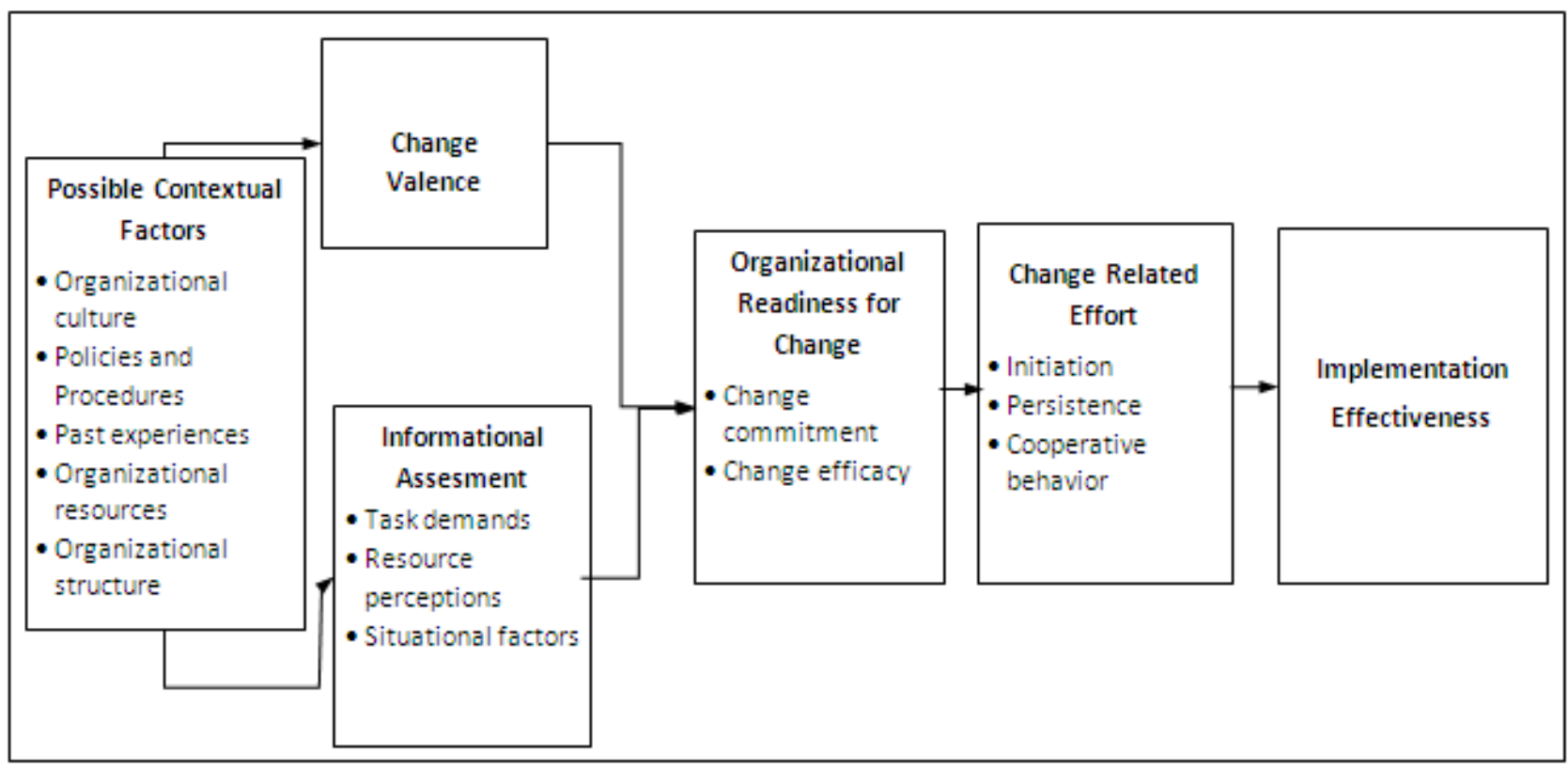

Figure 1. Determinants and Outcomes of Organizational Readiness for Change 


\subsection{Organizational Readiness for Change Dimensions}

As illustrated in Figure 1, this model suggests that organizational readiness for change is based on two dimensions: change commitment and change efficacy. As mentioned above, ORC refers to organizational members' shared resolve to implement a change and their collective ability to do so; respectively, these dimensions are known as change commitment and change efficacy $[9,23]$. In practical terms, readiness for change requires both willingness and a capability to change [11]. More recently, Nickel et al. [15] use the terms "collective commitment" and "collective efficacy" to designate these two dimensions.

'Collective Commitment' refers to whether organisation members, collectively, value the change: do members perceive that the change it necessary, and/or important, and/or beneficial? 'Collective Efficacy' relates to organization members' shared perceived ability to mobilise the necessary resources and cognitive abilities to execute the proposed change. (...) Barriers and facilitators in the form of task demands, resource availability, and situational/contextual factors, and the interactions between these three influence organisation members' perceptions of collective commitment and collective efficacy.

And Nickel et al. [15] specify that although collective efficacy and collective commitment are conceptually distinct, the two concepts are empirically related influencing each other and sharing some common but not completely overlapping factors. Holt et al. [11] add that they are "particularly salient when a change has system-wide aspects".

\subsection{ORC Determinants: Change Valence and Informational Assessment}

This model posits that organizational readiness for change is the product of two constructs: change valence and informational assessment. Weiner uses the concept Change Valence to measure organizational members' perceptions of the proposed change that is if this change meets a need, if there are interests to be gained either for them or for the organization. [23]. Drawing on the work of many authors, Jones, Jimmieson and Griffiths [24] define this value as the extent to which employees perceive positively the need for the company to change (i.e. change acceptance), and the extent to which they believe that the proposed changes are likely to have a positive impact on them and the entire organization. In a similar perspective, Weiner [9] states that the members of an organization may consider that a change is necessary because it either can solve a major problem, offer a benefit to the organization, its employees or customers, because it is consistent with the core values of the organization, and it has the support of management, organization leaders or peers. However, he stresses that individual motivations to engage in the implementation of a change is less important than the level with which the members of the organization collectively value a change project. For their part, Shaw et al. [23] identify perception of effectiveness and cost effectiveness while Bosworth et al. [25] add a fit with the organizations' mission, goals and values and a perceived increase in job satisfaction as other factors that are associated with change valence.

A second category of ORC determinants is regrouped under the concept of Informational Assessment [9, 23]. Determinants of this second dimension are based on the members' assessment of the information they possess regarding three aspects of a change project: knowledge about how the proposed change will have an impact on their tasks (task demands); perception of the resources (e.g., people, competencies, money, equipment, space, IT support) presently available and eventually needed to realize it (resources perceptions); and other situational factors such as time necessary to implement this change and it's timing, it's link and coherence with actual structures and actions currently under way, management support, and internal power dynamics generated by the nature and type of change to implement.

Finally, Weiner's model infers that these determinants are related to the degree of commitment and determination creates a desire among members of the organization to invest in the process of change through initiatives, persistent efforts and cooperative behavior, all leading to an effective implementation of change.

\subsection{Contextual Factors}

Weiner [9] and Holt et al. [11] have argued that the organizational contextual factors are a necessary dimension of readiness prior to a successful implementation of any change. Weiner's model also inferred that change valence and informational assessment will be influenced by contextual factors which could possibly vary from one organization to another and serve as facilitators or barriers to readiness for change. Following their research in the field of health care, Nickel et al. [15] also points out those contextual factors may amplify or dampen ORC.

Drawing on other researchers, Cinite [12] considers among possible factors, a culture that encourages and supports innovation, risk taking and training; flexible policies, rules and procedures for recruitment, selection, training, performance management and recognition; past change experiences; available resources (human, financial , material), sufficient and tangible funding, reward and incentive systems, and an encouraging climate and cultural environment. For their part, Holt et al. [11] claim that quantitative and qualitative structural factors will enhance or inhibit the implementation of a change.

As a result of recent research, here are some of the conclusions to which their authors arrive concerning some contextual factors. After a recent qualitative research involving eight hospitals, Nickel et al. [15] conclude that 
several factors that emerged from their data like limited human resources and staffing, cultural norms, administration support, and training have already been noted in other contexts. As for Shaw et al. [23], they found that change was facilitated because the program aligned with the values and goals of the organization. To conclude this section on contextual factors, the findings of Attieh et al. [14] summarizes well the state of knowledge on their importance, to the effect that they influence readiness and are considered a key dimension in the assessment of ORC.

\subsection{Inducing Organizational Readiness for Change: Management Practices}

According to our review of literature, managers must rely on a set of strategies, practices and interventions in order to generate the commitment of their staff and convince them that change is within reach. Cinite [12] considers these practices as potential determinants of ORC. Consistent with the model chosen, the actions to be taken should be focused on contextual factors in order to value the proposed change and to ensure that the means and conditions to achieve it are gathered. Relying on the authors consulted, it appears that the tasks to which managers are invited are mainly focused on four roles and on the mastery of skills related to them. These roles are change agent, communicator, guide, and decision maker. Some of the main actions and attitudes related to these roles are presented in the following paragraphs.

A manager must first communicate his vision of the needed and desirable organizational mutation [11, 12, 22]. For instance, the manager must justify, based on data, facts, problems, needs, and new obligations, the need for change. $\mathrm{He}$ should promote individual, organizational and community benefits in favor of this challenge, and be convincing in his advocacy that the status quo is no longer possible and the reason why certain behaviors and habits need to be changed. It is his responsibility to demonstrate that change is within their reach, consistent with certain values, guidelines and objectives of the organization and that certain practices and habits are already in line with the change. Without denying the limits and constraints related to its implementation, the manager must draw attention to the possible changes that can be brought to certain practices, organizational structures and administrative procedures in order to facilitate the process. It is also up to him to identify leads, opportunities, and resources that can help, support, promote and facilitate change $[12,21,22,26]$.

It is the manager's role $[6,12,21,26]$ to develop facilitation strategies supported by a detailed implementation plan that define roles and focuses on clearly articulated goals, objectives and desired outcomes, and detailed activities to be undertaken. It's up to him to specify the monitoring mechanisms that may allow adjusting along the road, to identify indicators to facilitate the assessment of the project and simplifying reporting of the level of progress. By so doing, it will be possible for him to express and justify the needs and the support required to ensure readiness for change. Finally, by setting up a participatory management structure [21] the manager has more chance to join and rally the driving forces of its organization, demonstrating his opening to listen and his flexibility with respect to decisions to be taken [12]. Haque [13] indicates that participation in decision-making can allow employees to have a sense of exercising power over the current change and some leeway in its development.

\section{Research Design and Methodology}

The data analyzed in this article come from three recent research conducted recently in the Province of Québec, Canada. A qualitative research approach was chosen so as to access interviewees' perceptions [27, 28]. The data collected through semi-structured interviews were aimed among others at identifying the factors that were facilitating or harming the mandate received by principals and their assistants to implement a new results-based and accountable management system. In doing so, this research also aimed to identify the skills and competencies required by school principals to accomplish their mandate. Specifically, these data were collected from key informants coming from nineteen school boards. Interviews were conducted with superintendent teams from five school boards; individual superintendents and assistant superintendents from twelve other school boards; twelve school board educational directors; seventeen human resources directors; thirty-three coaches of new school principals and assistant school principals; twenty-seven experienced school principals; and thirty-six new school principals and assistant school principals.

\section{Analysis and Interpretation of Data}

The analysis and interpretation of the data is structured according to the two specific research questions, namely: 1) what are barriers and facilitating factors likely to influence schools' readiness for change?; 2) what are the skills and competencies required by school principals to implement new regulation and evaluation practices that fit a school results-based management? The analysis and interpretation of data is based on Weiner's three dimensions of determinants relating to a collective Organizational Readiness for Change, namely Change Context, Change Valence, and Informational Assessment. With respect to the second question relating to the identification of skills and competencies, considering it overlaps the model's three dimensions, it will take into consideration the facilitators and barriers identified to answer the first question.

In reviewing this data analysis, it is important to remember Weiner's assertion to the effect that these three categories of determinants are not independent, but interrelated. For example, the assessment of the perceived availability of 
required resources (category: Informational Assessment) is not unrelated to the perception of the current school organizational resources (category: Contextual Factors). Moreover, some existing elements of the organizational culture can affect the value attributed to the change.

By concluding this analysis' introduction, it is worth reminding that, according to the hypothesis put forward by Weiner, these categories of determinants relating to the model's dimensions, should allow assessing the ORC of an organization, namely the degree of collective commitment and sense of efficacy over the intended change.

\subsection{Change Context: Barriers and Facilitators}

ORC model identifies five categories of factors: organizational culture, policies and procedures, past experiences, resources and structure [9]. With respect to organizational culture, many comments drew attention to the fact that generally, there are no formalized and systematic accountable practices in Québec's school system and therefore a new results-based management can only meet resistance from teachers and often from principals themselves. Teaching supervision and evaluation has always been based on means, not on results if it ever exists. This might explain the following comment from an interviewee: "The obstacles are ... resistance to change in classroom teaching practices, resistance to change in teacher evaluation practices." ${ }^{3}$ The data collected during the interviews also suggest that the new legislation imposing the signature of a conventional agreement on a success plan has caused insecure and recalcitrant teachers to take refuge behind their collective agreement to protect them. Some participants draw attention to the obligation for principals to comply with the teachers' collective agreement negotiated at the provincial and regional levels and reach an agreement with the union when it comes time to determine teacher training activities. According to them the procedures arising from this agreement explain the uncomfortable situation and continuing fear mainly felt by new principals to end up in front of union grievances whenever they want to innovate or initiate change with regard to teaching practices. The following comment will summarize the context in which the directions are caught: "As far as pedagogical innovation is concerned, we always have a sword of Damocles over our heads. Management must not make a false step in relation to the clauses of the collective agreement because it makes them submit to grievances on the nose."

In the opinion of some participants barriers also come from school board policies concerning the rotative allocation of school principals every four or five years. As pointed out by an interviewee, "you can't see results in a school if you are there less than six years. I've been here for four years and I'm just starting to see what influence I can have." The teachers' collective bargaining agreement also presents a

\footnotetext{
${ }^{3}$ It should be noted that all excerpts from the interviews that are reported in this text have been translated
}

similar barrier to implement such a crucial change, as indicated by one of the participants: "you develop your success plan with a school team and next year it's not even the same team".

Other comments insist on the rigid budgetary framework which does not allow allocating money to projects and activities related to the educational success plan while forcing directions and their team to be accountable for their student achievement. Many interviewees stress principals' complain about cuts to teacher training budget that greatly impaired the flexibility necessary to carry on change practices, underlying that more financial resources would likely be a facilitator in the implementation of a new culture. Nevertheless many comments identify moves from their organization to facilitate the advent of the desired change. They refer to the given importance by school boards to train and support the new results-based management. For example, interviewees will underline the appointment of coaches for new principals, training sessions to improve principals' managerial and educational skills, the implementation of professional learning communities for principals and teachers, helping educational and human resources consultants, and computing systems to inform schools about students' results.

As we will see now see, all these contextual factors will influence the way organizational members perceived the value of the proposed change and assess their chance to implement it.

\subsection{Change Valence: Barriers and Facilitators}

It is important at the outset to recall the meaning given by the authors to the concept of Change Valence. It refers to the degree to which organizational members value the proposed change, which means they perceive positively the need for change, perceive a benefit to change for them and the organization, and assess that this change is consistent with the core values of the organization. The following sections report the main barriers and facilitators and identified during the interviews conducted.

Two main types of barriers emerge from the data analysis. The first group expressed a sense of concern toward a negative benefit for principals to implement such a drastic cultural change. Among the difficulties facing school managers there is that of convincing teachers to review their teaching practices while they often feel "not having the required knowledge" to do so. Several interviewees allude that the implementation of a results-based system is a very high step to take for principals and that they feel a high level of insecurity. Some comments even put forward that some principals' lack of motivation was attributable to the fact that this change was contrary to their values. One participant indicated in this regard they "were uncomfortable because, when they were teachers, they did not like to be assessed". To them, "the implementation of a management agreement based only on students' results was appalling". 
A second group of barriers also relates to the perceived negative benefit. It refers to principals' feelings of impotence and incapacity about changing teacher practices. As one interviewee mentioned, they fear that "implementing results-based management implications relating to reporting and accountability would add to the refusal of teachers to collaborate". Furthermore he argues, inter alia, that "the low level of motivation for the problems of student retention and achievement among teachers could go as far as "to refuse to sign the Convention Management and the Educational Success Plan between schools and the regional boards". The same teachers' attitude regarding supervision practices by principals was also mentioned as a major barrier. Such a type of regulation would be a major challenge for a majority of principals that have to earn a pedagogical credibility with their staff. Another participant considers that "the lack of scientific support" linked to student achievement factors weakens the principals' pedagogical discourse and add another crucial barrier.

It is, however, important to stress some facilitators that were mentioned such as the fact that improving students' achievement is a shared value among schools' managers and teachers and that more resources and support will likely be seen as beneficial to the school. Some interviewees also perceived in the implementation of the new regulatory system an opportunity to enhance the principals' credibility and educational leadership. One of them will go as far as to say that if a principal successfully plays his role of leader, "he could make a difference in the classroom".

\subsubsection{Informational Assessment of Tasks Demandsand Resources: Barriers and Facilitators}

According to the review of literature, informational assessment is a broad concept that refers to information employees possess regarding three aspects of a change project: knowledge about what tasks are involved and need to be performed (task demands), perception of resources and time available and needed (resources perceptions), and other situational factors. These determinants would influence the will and determination of a school team to believe in the possibility of implementing the proposed change. In this section, we first address tasks demands and resources determinants.

Many interviewees identified the enlargement and cumbersomeness of principals' role as a significant challenge that hides several barriers. They mentioned new rules and procedures the school staff will have to accept and follow, and demanding tasks principals will have to perform in order to implement a results-based management in their schools. They pointed tasks related to change planning, proposing measurable goals, objectives and targets to be reach and linking these to the school mission, operationalizing relevant strategies, ensuring necessary resources, putting in place an informational system to monitor and follow the progress of student achievement, mobilizing and convincing his staff to accept new means to supervise, coach and evaluate the teaching program and class practices. Even though such tasks may seem clear at first sight, translating them into action is perceived complex and less obvious. A last barrier is worth mentioning. The implementation of the new results-based system will require training activities and coaching support. It would be difficult for school staff to perceive he could count on any new money to carry change practices. But some interviewees referred to the "rigid budgetary framework which does not allow teachers to allocate money to projects and activities related to the educational success plan", while forcing school staff to be accountable. Furthermore, they stressed the important $25 \%$ cuts made to the teacher training budget".

There were comments that pointed at facilitators. Most interviewees focused on resources put in place to train and support principals and their staff. Many regional school experts like superintendents, central educational consultants and human resources specialists were mobilized. Principals' and teachers' learning communities were put in place to facilitate the implementation of new supervision and evaluation procedures and to encourage new teaching practices. Of course during training meetings school managers received full of "how to" advices and warnings on how they should proceed and act to implement the new results-based and accountable system. Some were quite paternalistic like "be perseverant" and "courage, put on your pants" while others were somehow an apology of their management style. A superintendent was proud to argue "We feed our principals regularly, we give them result examples. They are given tools by giving them information. For example, all directions receive their own dashboard." However few empowered them to do their job given the unfavorable general context for its implementation. Another facilitator mentioned by some interviewees referred to the importance for a school board to clearly express its expectations toward the content of a school student achievement plan, the required forms to complete and the time schedule to be respected.

\subsubsection{Situational Factors: Barriers and Facilitators}

By situational factors Weiner refers to other determinants organizational members take into consideration and which influence their commitment and level of investment in the change project. Among those mentioned in the literature there are the project's change timing, its link and coherence with actual structures and actions currently under way, management support, and internal power dynamics generated by the nature and type of change to implement.

Most of the determinants identified by interviewees relating to the last category of determinants were perceived by school principals as major barriers. They had a link with the climate of relations between management and teachers, and between sub-groups of teachers. Repeatedly, interviewees underline the uncomfortable situation and continuing fear of principals. One of them mentioned that whenever principals want to innovate or initiate change with regard to teaching practices they fear "to end up in front of union grievances". According to another participant this 
situation is constantly present in view of the fact that a section of the collective agreement "imposes directions to agree with the union" when it comes time to determine teacher training activities. Factors such as "intimidation of principals by union representatives" and "fear engendered by union pressure" against teachers who wish to collaborate with school managers, proceed to change their teaching practices, or work for the implementation of new regulatory practices. Such working relationships were to prevent principals, and mainly newcomers from playing their roles and prevent collaborative staff members to perceive the difficulties that these divisions would raise during the eventual implementation of the desired change. Finally, according to many stakeholders interviewed, change rhythm and lack of time required to implement new regulatory practices based on students' achievement results is another barrier that plays on the feasibility of this cultural change. As mentioned by one of them, it is more or less an impossible challenge for principals to create a collective will while "rapidly and successfully attempting to fix new success plan targets, assure financial and professional support, and propose new means and procedures to monitor the teaching practices changes and assess the school level of success".

\subsection{Basic Competencies Related to the Management of an Organization's Cultural Change: Skills to Master}

According to Weiner's model [9] managers could influence their staff perceptions of some ORC determinants through the way they lead change. However their interventions would require the mastery of specific skills. As was mentioned earlier, this model points at three groups of determinants which may, on the one hand, lead to collective commitment and determination of their staff members to make change (change commitment), and secondly to the conviction of their collective capacity to implement change (exchange efficacy). The qualitative data collected refer to basic skills that school managers must master to manage organizational change and knowledge relating to the object of change itself, namely in the case of interest here, the regulatory practices a school needs to implement in order to comply with an accountable management approach based on students' achievement results.

The basic competencies to manage the dynamics of an organization's cultural change revolve around key skills frequently discuss in the literature bearing on organizational change. Those more often mentioned relate to mobilizing the school staff, setting up an informational strategy that will facilitate communications with staff and organization's political instances, sharing and delegating his decision-making authority, and developing a collective competence for successful change process $[12,13,21,29$,

30].

According to the data collected from schools' stakeholders, the main specific competencies principals should master are:

a) Help their staff understand the political, social and economic reasons underlying the imposed change; b) Justify this change relying on a pedagogical argument, on facts and data;

c) Clarify the leeway and flexibility that the school benefits;

d) Communicate a vision of the school's educational mission" in order to rally his school staff behind the goals and priorities of the success plan;

e) Analyze the data needed to establish priorities and outcomes that will give meaning to actions required to implement new practices and ways of doing;

f) Ensure staff cohesion around this vision;

g) Promote the possible gains that change will bring to the school and its members;

h) Demonstrate the relationship between the intended change and practices that already exist;

i) Negotiate roles and responsibilities with his staff, specify the tasks to be performed, as well as school management processes and procedures and teaching practices to be revised;

j) Establish the operational feasibility of the change project by assuring relevant decisional structures and financial, human and technological resources;

k) Show his willingness to adopt a partnership and participatory management approach, by informing transparently, recognizing the expertise of his employees, respecting their need for autonomy, facilitating the expression of different and differing points of view, solving conflicts, and searching consensual decisions: and inevitably inform, explain and justify the results achieved.

Here is how an interviewee summarizes in his own words the challenge facing a school principal who has to manage the change imposed by the recent legislation:

Principals must learn to drive change and driving change is to have a clear vision of what you want, what are the resources available to me, how to motivate my teachers, and did I draw up a strategic plan. All these tasks must be performed and are essential ingredients to drive a change. He has to master them all a lot much.

\section{Discussion and Conclusions}

This article aimed to identify from the perspective of different groups of actors interviewed, firstly what were the barriers and facilitating factors influencing the level of a school readiness to implement a new results-based management approach, and secondly what competencies school principals must perform to lead their schools in such a cultural change context. Data analysis relied on Weiner's three dimensions of determinants relating to a collective Organizational Readiness for Change (ORC), namely Change Context, Valence, and Informational Assessment. According to the hypothesis put forward by Weiner, these categories of determinants should allow assessing the ORC 
of an organization, namely the degree of collective commitment and sense of efficacy over the intended change. The data on context factors have highlighted barriers related to organizational culture like no formalized and systematic accountable practices, teaching supervision and evaluation mainly based on means not on results, and the use of the Teachers' Collective Agreement to counteract any change relating to teaching practices. Other barriers came from principals and teachers allocation policies and financial procedures insensitive to unforeseen needs generated by changes and innovations. Facilitators were related to central management and services support, training sessions to improve principals' managerial and educational skills, appointment of coaches for new principals, implementation of professional learning communities for groups of principals and teachers.

Concerning data relating to Change Valence, barriers referred to principals' perceived negative benefit in the implementation of a drastic cultural change. The anticipation of a failure and its consequences on the school climate, an unrealistic step to straddle, predictable teachers' refusal to collaborate, principals uncomfortable feeling with the values behind the new management approach, lack of scientific support to convince teachers and feelings of impotence about changing teaching practices are all factors influencing how organizational members perceived change value. To offset these barriers, some facilitators such as the fact that academic achievement is an important value for school staff and a chance for principals to increase their educational leadership were put forward.

Enlargement and cumbersomeness of principal's tasks in leading the implementation of a results-based management was perceived as a significant challenge hiding several barriers. They may appear simple and obvious to name, but translating them into action is perceived as being less obvious, more complex and heavy to carry on. If many interviewees saw training and support offers by central administration as a possible facilitator, as a whole it was perceived not sufficient and appropriate given the unfavorable context in which the principals must evolve. Other barriers like the short timetable given to implement the proposed change and the financial constraints faced by schools over the past two decades are of concern. To complete the staging in which most principals play their role, the climate of relations between management and teachers, and between sub-groups of teachers is perceived as a major handicap.

As far as competencies deemed basic to meet the demands of such a significant cultural change, the qualitative data collected refer to skills school principals must master to manage organizational change and knowledge relating to the object of change itself, namely in the case of interest here, the regulatory practices a school needs to implement in order to comply with an accountable management approach based on students' achievement results.

The data analysis carried out and the results obtained lead to make some remarks and suggestions with regard to managing organizational readiness of a major and complex cultural change and the model we used to identify and classify these data. If Weiner's three dimensions are relevant to analyze and to a certain extent predict the way an organizational change will be effective, the data analysis made leads us to a few considerations. When we undertake a context's diagnosis of facilitating factors and barriers in which change is to take place, the magnitude of this change and its impacts seem to have a proportional effect on Change valence's assessment by members of an organization and the probability that it can be realized. The multitude and diversity of perceptions might vary considerably depending on the importance of stakeholder groups, the nature of the functions they occupy and their power over the decisions regarding the proposed change. This may make it more difficult to measure the degree of openness to this change, except if there is a consensual perception and evaluation which was not the case of the cultural change we analyzed in this paper. In another vein, the factors and determinants of Weiner's three dimensions would gain to be more precisely defined in order to improve data classification.

Finally, the data collected came from key informants from nineteen school boards. The analysis did not take into account the work functions of interviewees, nor the school boards or schools in which they worked. It is important to remember that Weiner's model inferred that some contextual factors could possibly vary from one organization to another. The data analysis made so far convinces us to continue by taking into account the functions performed by the interviewees and the school board to which they belong.

\section{Acknowledgements}

The author would like to thank Mrs. Lise Corriveau and Mr. Marc Garneau for their contribution to this research.

\section{REFERENCES}

[1] Caron A. L'école ne sera plus jamais pareille! Savoir, 2000, vol. 5 , no. 3 , p. 3 .

[2] Corriveau L. Identification professionnelle ou suridentification à la profession? La situation de directrices et de directeurs d'établissements scolaires québécois. Éducation et francophonie, 2004, vol. 32, no. 2, pp. 95-110.

[3] Fortin R. L'insertion professionnelle des nouvelles directions d'établissement d'enseignement. Montréal: FQDE, 2006.

[4] St-Germain M. Étude des divergences entre le temps de travail réel et le temps de travail souhaité chez les directions d'établissement d'enseignement. Montréal : FQDE, 2013.

[5] Lalancette L. Gouvernance scolaire au Québec: représentations chez les directions d'établissement d'enseignement et modélisation. Montréal : FQDE, 2014. 
[6] Rondeau A. L'évolution de la pensée en gestion du changement : leçons pour la mise en œuvre de changements complexes. Télescope, 2008, vol. 14, no. 3, pp. 1-12.

[7] Goksoy S. The role of the educational manager's in the management of change. International Journal of Academic Research, Part B, 2013, vol. 5, no. 6, pp. 188-193.

[8] Schein E. H. Organizational culture and leadership. San Francisco : Jossey-Bass, 2004.

[9] Weiner B. J. A theory of organizational readiness for change, Implementation Science, 2009, vol. 4, no. 67, pp. 1-9.

[10] Vakola M. Multilevel readiness to organizational change: A conceptual approach. Journal of Change Management, 2013, vol. 13, no. 1, pp. 96-109

[11] Holt D. T., Helfrich C. D., Hall C. G., Weiner B. J. Are you ready? How health professionals can comprehensively conceptualize readiness for change. J Gen Intern Med, 2010, vol. 25 (Suppl 1), pp. 50-55.

[12] Cinite I. Measurement of perceived organizational readiness for change and employees' attitudes toward change in the public sector. Doctoral thesis. Ottawa: Eric Sprott School of Business Carleton University, 2006.

[13] Haque MD M. A study of the relationship between the learning organization and organizational readiness for change. Doctoral thesis. Pepperdine University. 2008.

[14] Attieh, R, Gagnon, M-P, Estabrooks, C. A, Légaré, F., Ouimet M., Roch, G., Ghandour, E., and Grimshaw, J. Organizational readiness for knowledge translation in chronic care: a review of theoretical components. Implementation Science, 2013, 8:138, pp. 1-9.

[15] Nickel N. C., Taylor E. C., Labbok, M.H., Weiner, B. J. Williamson, N. E. Applying organisation theory to understand barriers and facilitators to the implementation of baby-friendly: A multisite qualitative study. Midwifery, 2013, 29, 956-964.

[16] Gagnon M.P., Attieh R., Ghandour E.K., Légaré F., Ouimet M., Estabrooks, C. A., Grimshaw, J. A Systematic Review of Instruments to Assess Organizational Readiness for Knowledge Translation in Health Care. PLoS ONE, 2014, vol 9, no. 12, pp. 1-32.

[17] Weiner B.J., Lewis M.A., Linnan L.A. Using organization theory to understand the determinants of effective implementation of worksite health promotion programs, Health Education Research, 2009, vol.24 no.2, pp. 292-305.

[18] Armenakis A. A., Harris S. G., Mossholder K. W. Creating readiness for organizational change. Human Relations, 1993 , vol. 46, no. 6 (June), pp. 681-703.

[19] Haque MD M. A study of the relationship between the learning organization and organizational readiness for change. Doctoral thesis. Pepperdine University. 2008.

[20] Eby L. T., Adams D. M., Russell J. E. A., Gaby S. H. Perceptions of organizational readiness for change: Factors related to employees' reactions to the implementation of team-based selling. Human Relations, 2000, vol. 53, no. 3, pp. 419-442.

[21] Chase M. L. Instrument development: assessing solutions for managing change and organizational readiness. Doctoral thesis. Fort Collins: Colorado State University, 2009.

[22] Shea C. M., Jacobs S. R., Esserman D. A., Bruce K., Weiner B. J. Organizational readiness for implementing change: a psychometric assessment of a new measure Implementation Science, 2014, vol. 9, no. 7, pp. 1-15.

[23] Shaw, R. J., Kaufman M. A., Bosworth H. B., Weiner B. J., Zullig L. L, Lee, S.-Y. D., Kravetz, J. D., Rakley, S. M., Roumie, C. L., Bowen, M. E., Del Monte, P. S., Oddone, E. Z. and Jackson, G. L. Organizational factors associated with readiness to implement and translate a primary care based telemedicine behavioral program to improve blood pressure control: the HTN-IMPROVE study. Implementation Science, 2013, 8:106, pp. 1-13.

[24] Jones R. A., Jimmieson N. L., Griffiths A. The impact of organizational culture and reshaping capabilities on change implementation success: The mediating role of readiness for change. Journal of Management Studies, 2005, vol. 42, no. 2, pp. 361-386.

[25] Bosworth HB, Olsen MK, Dudley T, Orr M, Goldstein MK, Datta SK, McCant F, Gentry P, Simel DL, Oddone EZ: Patient education and provider decision support to control blood pressure in primary care: a cluster randomized, $\mathrm{Am}$ Heart J, 2009, vol. 157, no. 3, pp. 450-456.

[26] Malone S. A. Creating Organizational Capacity for Continuous and Adaptive Change. Doctoral thesis. Benedictine University, 2007.

[27] Creswell, J.W. Research Design: Qualitative, Quantitative, and Mixed Methods Approaches, 4th Edition. London: Sage, 2013.

[28] Karsenti, T. et Savoie-Zajc, L. La recherche en éducation, étapes et approches. Québec : Erpi, 2011.

[29] Armenakis A. A., Harris S. G. Crafting a change message to create transformational readiness. Journal of Organizational Change Management, 2002, vol. 15, no. 2, pp. 169-183.

[30] Battilana J., Gilmartin M., Sengul M., Pache A.-C., Alexander J. A. Leadership competencies for implementing planned organizational change. The Leadership Quarterly, 2010, vol. 21, no. 3, pp. 422-438.

[31] Habeck M. M., Kröger F., Träm M. R. Après la fusion. 7 clés pour réussir l'intégration. Paris : Dunod, 2001. 